\title{
EAD SIM, MAS COM QUAL BIBLIOTECA?
}

\author{
Solange Puntel Mostafa
}

\begin{abstract}
Resumo
Discute a importância da biblioteca virtual para o ensino a distância de qualquer curso; para tal o bibliotecário deve ser elemento indispensável na equipe de EAD uma vez que ele conhece as fontes e as formas de organização da informação, o que lhe possibilita atuar inclusive como tutor. Recomenda-se a intervenção do bibliotecário já na fase de planejamento do curso de tal forma que a biblioteca resultante seja um produto/processo tão importante quanto os demais componentes curriculares e customizada ao curso em questão. Destaca a gestão da informação nos sites educacionais, essa outra modalidade de EAD na formação continuada de professores.
\end{abstract}

Palavras-chave

Ensino a distância; Bibliotecas; Educação

\section{DISTANCE EDUCATION YES, BUT WITH WHICH LIBRARY?}

\begin{abstract}
Discuss the importance of the virtual library for the education of any course argues in the distance; for such the librarian must be indispensable element in the Distance Learning team a time that it knows the sources and the forms of organization of the information, what he makes possible to it to also act as tutorial. Intervention of the librarian already in the phase of planning of the course of such form sends regards to it that the resultant library is one product/process so important how much the excessively component curricular ones and customizing to the course in question. It detaches the management of the information in the educational sites, this another modality of Distance Learning in the continued formation of teachers.
\end{abstract}

\section{Keywords}

Distance learning; Libraries; Education

1 Parte deste artigo foi publicada como capítulo no livro:

SILVA, Marco (Org.). Educação on-line: teorias, práticas, legislação, formação corporativa. São Paulo: Loyola , 2003.

(C) Revista Digital de Biblioteconomia e Ciência da Informação, Campinas, v. 1, n. 1, p. 1-11, jul./dez. 2003 - ISSN: 1678-765X. 


\section{BIBLIOTECÁRIOS NA FAMOSA EQUIPE DE EAD}

Mais e mais os bibliotecários têm reivindicado a sua participação como parte integrante da famosa equipe de EAD (DONADEL, 2002; LANGE, 2001). A responsabilidade do bibliotecário com o usuário é semelhante à do professor com o aluno no desenvolvimento da metacognição. Para começar qualquer busca de informação inicia-se pela reflexão sobre o quê se conhece. Qual é o assunto sobre o que se quer pesquisar. $O$ cotejo com os resultados da busca faz mudar a própria pergunta da busca, num processo muito semelhante ao teste de hipóteses do projeto de pesquisa pós-graduada ou do projeto de trabalho escolar. A interação do bibliotecário com os professores e alunos possibilita desenvolver a metacognição, o teste de hipóteses, a argumentação. É uma interação que abre para o paradigma das múltiplas fontes. O bibliotecário nesse caso tem um trabalho que é o de um professor ensinando a biblioteca. A 'transgressão e mudança na educação', segundo Hernandez (1998, p. 79) é possibilitar ao educando 'ter acesso, analisar e interpretar a informação', o que via de regra é uma recomendação presente na maioria dos autores educacionais contemporâneos; claro que a informatização das últimas décadas e especialmente o surgimento da Internet reforçou a importância da informação como produto e como processo em todas as esferas da existência. Mormente na escola cuja especificidade é a transmissão de conhecimentos agora entendida como um processo de produção e de construção.

As chamadas 'fontes de informação' dantes tão renegadas aos capítulos finais dos livros, agora estão presentes no corpo dos textos e são partícipes de estratégias de ensino e aprendizagem, como em Hernandez (1998), ao caracterizar o projeto de trabalho:

- parte-se de um tema ou de um problema negociado com a turma.

- inicia-se um processo de pesquisa;

- buscam-se e selecionam-se fontes de informação;

- estabelecem-se critérios de ordenação e de interpretação das fontes;

- recolhem-se novas dúvidas e perguntas;

- $\quad$ estabelecem-se relações com outros problemas; 
- representa-se processo de elaboração do conhecimento que foi seguido;

- recapitula-se (avalia-se) o que se aprendeu;

- conecta-se com um novo tema ou problema.

$\mathrm{O}$ mesmo receituário pode ser encontrado na literatura especializada dos bibliotecários, a exemplo de Brem e Boyes (2000) em cujo título vemos a expressão 'senso crítico' (critical thinking); esse senso crítico seria alcançado nos passos delineados pela autora como sendo metacognição, teste de hipótese e argumentação. O aluno ou professor quando vão à biblioteca deparam-se com ordenamentos de certa forma já interiorizados no seu próprio processo de ensino-aprendizagem: a busca por palavra em um catálogo, o nome de autores ou os títulos dos livros. A questão é que sempre um nível de aprendizagem é necessário porque são todos processos representacionais envolvendo portanto diferentes níveis de abstração. Toda vez que se classifica livros, está-se gerenciando conhecimentos. Toda vez que se faz catálogos, está-se gerenciando conhecimentos. Agregando valor.
Aumentando o valor, aumenta o acesso. O catálogo ou o índice é um dispositivo de diminuir o tempo para se chegar à obra. Como o resumo. Encurta caminhos, faz atalhos. Faz chegar mais rápido. Então enriquece a obra porque dá mais visibilidade. As pesquisas bibliotecárias demonstram que mesmo em nível internacional, as estratégias de busca realizadas na tela dos computadores das bibliotecas ainda são pobres e mal elaboradas (BREM; ANDRÉA, 2000). Cuenca (1998, p. 293) realiza um estudo na Faculdade de Saúde Pública da Usp para avaliar a capacidade do usuário final em acessar as bases de dados em CD-ROM Medline e Lilacs, após treinamento oferecido pelo Programa Educativo da biblioteca e o resultado é que a maioria de $65 \%$ dos sanitaristas entre professores e alunos conseguem autonomia para acessar as bases de dados. Os demais se dividem entre os que soliticitam ajuda do intermediário (bibliotecário ou 'search analyst') e os que desistem de consultar as bases). Se esses dados forem transportados para o Ensino a Distância, parte da evasão no EAD pode estar relacionada com a dificuldade do acesso a fontes de informações bibliográficas, justamente num momento de abundância 
informacional. As bases de dados, ao contrário, tornam-se cada vez mais ricas em informações, mas esse crescimento não corresponde a adequadas estratégias de como explorá-las. A complexidade envolvida na busca de informações é a mesma de qualquer metodologia de projetos ou de trabalho na escola. Há um papel reservado ao professor no agenciamento do processo de conhecer, da mesma forma que há sempre um papel reservado ao bibliotecário no agenciamento das fontes eletrônicas no Ensino a Distância.

\section{BIBLIOTECÁRIOS E FORMAÇÃO DE PROFESSORES}

A prática dos bibliotecários com acesso remoto é antiga e anterior à Internet. Mas com o boom do EAD e com o próprio desenvolvimento das tecnologias de rede, novas preocupações surgem no cenário da biblioteca para subsidiar um EAD. Por exemplo, as bibliotecas se vêem envolvidas com obtenção e pagamento de direitos autorais, com treinamento de referência online e por telefone e mais importante, vêem-se envolvidas com renegociação de contratos com fornecedores de base dados online para suprir o acesso legal aos estudantes off-campus (GÓIS et al, 2001, p.21). Mas tudo isso são bastidores de bibliotecas. Na tela o aluno de EAD precisa de Biblioteca Virtual. Simplesmente porque biblioteca é informação organizada. Nesse sentido a Internet é também uma grande biblioteca. E pode ser explorada enquanto tal e enquanto fonte para a construção de bibliotecas virtuais dos cursos de EAD. Nos dois casos, a presença do bibliotecário é tão importante quanto a presença do professor no ensino e aprendizagem. Donde a figura do bibliotecário na famosa equipe de EAD. De tal sorte que a biblioteca virtual do curso de EAD seja um produto costumizado ao curso e construído conjuntamente no planejamento do próprio curso. Veja por exemplo a proposta da biblioteca virtual do curso de Gestão e Desenvolvimento de Escolas (GDE) em Góis et al (2001). Para que os educadores assumam as aulas-pesquisa ou aulasinformação (MORAN, 2000, p. 46-47), pode-se contar com o auxílio de bibliotecários os quais podem ter uma participação decisiva na formação dos professores. Consulte, por exemplo, a Biblioteca Virtual da Turma de 2001, construída por alunos de Mestrado em Educação da UNIVALI (Universidade do vale do Itajaí), nos conteúdos de suas 
dissertações de mestrado, alguns com pouca familiaridade em informática (www.geocities.com/spmostafa/UNIVALI. html); os mestrandos foram introduzidos às estratégias de busca online.

Estratégias de busca de informações na Internet são portanto estratégias de aprendizagem de um saber muito valorizado hoje em dia: o saber dos endereços no sentido de como chegar até eles na proposta de Lyotard (1990, p. 91-92):

[...] um manejo mais refinado deste jogo de linguagem que é a pergunta: onde endereçar a questão, isto é, qual a memória pertinente para o que se quer saber? [...].

A pedagogia usa, portanto estratégias muito semelhantes às estratégias informacionais, dada à semelhança do processo informacional/pedagógico na sala de aula e na biblioteca. A professora do ensino fundamental ou médio desenvolve no aluno as mesmas capacidades superiores de raciocínio que o bibliotecário desenvolve no usuário de biblioteca. Para desenvolver no aluno capacidades de abstração necessárias ao pensamento superior e aos sentidos complexos, que são os sentidos científicos, é necessário aquele detour que vai dos dados, passa pelas informações e chega ao conhecimento.

$\mathrm{Na}$ escola, mais do que em qualquer outro lugar, é preciso levar a sério o aviso que diz: "página em construção". Na página em construção e no convite ao internauta para "melhorar nossa página" estão as duas principais funcionalidades da Internet: ela é a um só tempo repositório de informações e meio de comunicação; por isso, o seu conteúdo está em permanente construção.

\section{BIBLIOTECÁRIOS E AS FONTES COMPLEMENTARES EM EAD}

No Brasil, de acordo com a Associação Brasileira de Educação a Distancia (ABED) existem 59 instituições de vários níveis educacionais oferecendo cursos a distância (DONADEL, 2002, p. 35). A pesquisa acima demonstra que os serviços e produtos das bibliotecas das instituições que oferecem cursos EAD são limitados para atender o aluno remoto. Por exemplo, os serviços tradicionais de biblioteca como:

a catalogação na fonte, o empréstimo domiciliar, o empréstimo entre bibliotecas, a pesquisa bibliográfica, a orientação bibliográfica [...] são os serviços mais oferecidos pelas bibliotecas, mas eles ainda não 
apresentam atualizações tecnológicas significativas (DONADEL, 2002, p. 55).

Donde as recomendações da autora para que se explore mais a pesquisa bibliográfica online. $\mathrm{E}$ se direcione o e-mail para serviços de referência digital do tipo "pergunte ao bibliotecário" em tempo real, como o observado pela autora na biblioteca americana do MIT (Massachusetts Institute of Technology) com um serviço em tempo real do tipo "Ask us" funcionando como um chat (DONADEL, 2002, p. 36).

A preocupação da Ciência da Informação com as equipes de EAD é tal que a pesquisa participante já desponta como opção nas dissertações da área. Assim, Lange (2001) se matricula em dois cursos brasileiros a distância de formação de professores (especialização), um totalmente a distância e outro semipresencial para observar como os cursos lidam com o acesso às bibliografias ou fontes eletrônicas de informação. $\mathrm{O}$ resultado é que nos dois cursos os alunos sentiram necessidade de "links, sites, bibliotecas virtuais, base de dados para [...] recuperar a informação desejada" (p. 107). Com uma ironia: o curso semi-presencial disponibilizou mais recursos (endereços de homepages, apesar de nem sempre apropriados) do que o totalmente a distância.

Como tutora em curso de formação de professores em Educação a Distância (totalmente a distância) observei a necessidade de fontes complementares as do texto impresso que o aluno recebe. Este texto, mesmo que esteja disponibilizado online para os alunos fazerem download, ele não contempla a estrutura de hipertexto para que os alunos naveguem em outras fontes. Aí vai uma recomendação para os planejadores dos cursos de EAD, especialmente para os autores dos textos. $\mathrm{Ou}$ o curso integra os bibliotecários na equipe para que eles construam essa biblioteca em tempo hábil e o aluno não seja simplesmente remetido à bibliotecamãe da instituição. Ou os autores do material impresso construam seus textos com o paradigma das múltiplas fontes. O observado por Lange (p. 96) é o laissezfaire do tutor: "quanto às referências bibliográficas, uns auxiliam os outros". E a famosa equipead, como pode auxiliar? 


\section{ENQUANTO SEU LOBO NÃO VEM...}

Destacamos cinco formas básicas de procurar informação na Internet: 1) através dos motores de busca onde encontramos na maioria deles a estrutura de sumário e índice de um livro; 2) através das bases de dados bibliográficas que traz a segurança do texto revisado pelos pares; 3) através das bibliotecas virtuais como as pioneiras do Prossiga/CNPq e da maioria das bibliotecas universitárias que tem disponibilizado, além do seu catálogo de livros, também um conjunto de links por assunto, que outra vez podemos chamar de biblioteca virtual da Biblioteca $x$. Na recente pesquisa já mencionada (DONADEL, 2002) 67\% das bibliotecas brasileiras das instituições que oferecem EAD estão disponibilizando esses links, que segundo a autora estão quase sempre atualizados. Não são, porém customizados a nenhum curso específico de EAD; 4) através das bibliotecas digitais: as bibliotecas universitárias estão mais e mais digitalizando as teses e dissertações dando origem a bibliotecas digitais da sua produção científica, um passo que deverá alavancar e muito a pesquisa científica no Brasil. Porém, até a presente data, ainda são poucas as iniciativas (apenas $2 \%$ das
IES brasileiras que oferecem EAD); por fim através dos 5) catálogos de bibliotecas reais disponibilizados na Internet. Dentre as instituições que oferecem cursos a distância no Brasil, 69\% disponibilizam o catálogo na internet até a presente data. $\mathrm{O}$ serviço porém de renovação e reserva de livros online não chega a ser oferecido por $20 \%$ das bibliotecas das instituições que oferecem EAD no Brasil.

\section{SITES EDUCACIONAIS COMO PONTO DE ENCONTRO DE SABERES}

Outra modalidade de ensino a distância recente está acontecendo através dos sites educacionais. De maneira geral, podemos dizer que as páginas das Universidades, assim como as páginas das Escolas e Colégios são sites educacionais. Ambas as instituições, ao colocarem suas páginas na Internet querem divulgar seus serviços e cursos que oferecem à comunidade.

Há, porém uma outra vertente de site educacional que tem se desenvolvido na web e que se constituem em empresas que não são nem escolas, nem universidades e nem tampouco cursos formais. São fenômenos novos desenvolvidos a partir das redes telemáticas e da Internet. 
Fenômenos virtuais. Assim se encaixam os 'sites educacionais' propriamente ditos ou portais educacionais.

Os sites educacionais são uma espécie de escola nova virtual : são instâncias de aprendizagem novas, onde encontramos textos comentados e selecionados como se estivéssemos sendo orientados por um professor. E até a própria conversa on-line com esse professor pode acontecer em momentos combinados. Ficando o processo todo muito parecido com a escola real. Mas trata-se de uma 'escola virtual'. Nela você pode ler textos selecionados, conversar com colegas e professores e publicar seus trabalhos ou trabalhos de alunos da escola; o ponto forte dos sites educacionais é poder ter entre seus clientes o maior número de escolas cadastradas. Pois as escolas são tão importantes para os sites educacionais como os alunos são para a unidade escolar. As escolas 'alimentam' os sites com os seus próprios projetos e com sua demanda por serviços especializados ofertados pelos sites. $\mathrm{Da}$ mesma forma que as bases de dados científicas dependem da produção científica dos pesquisadores gestada principalmente nas universidades.

\section{AS BIBLIOTECAS VIRTUAIS NOS SITES EDUCACIONAIS}

Variam muito entre os sites as formas e compreensão do que venha a ser biblioteca virtual do site. Em alguns sites analisados há sempre uma forma de organização dos textos porém nem sempre suportada por banco de dados para possível recuperação (o mais comum é uma estrutura de hipertexto); Poucos sites lincam para bibliotecas mais acadêmicas a exemplo Site Educarede

(http://www.educarede.org.br/educa/index.cfm ) que nos seus Educalinks aponta, entre outras, para Bibliotecas de teses e dissertações da USP e o Site Eaprender (<http://eaprender.ig.com.br/home.aspo $>$ ) qual remete à Biblioteca Virtual do INEP que é uma das temáticas do CNPq. Volta e meia vê-se também nos sites a referência à Biblioteca Virtual do Estudante Brasileiro, como no caso do site Aprendiz (http://www.uol.com.br/aprendiz/n_coluna s/c_buarque/index.htm). Mas no geral, o que temos nos sites é uma biblioteca virtual ressignificada. Até porque os textos dos sites representam um ponto de encontro entre a Universidade e a Escola e portanto também são textos ressignificados, retrabalhados, didatizados, 
por assim dizer, mais curtos e de natureza didática. É possível que a estrutura de bancos de dados seja uma estrutura mais difícil para o ambiente escolar do que a estrutura de hipertexto. Os textos são então distribuídos pelas páginas do site a exemplo do Site Centro de Referência Educacional (CRE)

(http://members.tripod.com/lfcamara/)

onde na capa do site encontra-se chamada para uma monografia em cujo link somos levados para uma sessão de artigos do site onde estão disponibilizados na forma de um sumário vários capítulos da dita monografia como se fossem artigos independentes.

A variedade de formas de organização da informação nos sites revela então uma especificidade da informação escolar que talvez fique mais bem resolvida no conceito de 'transposição didática' da engenharia didática francesa. Isso não dispensa o trabalho bibliotecário de organização, mas requer uma outra organização e uma outra compreensão do saber escolar a que os bibliotecários nem sempre estão acostumados dada a sua familiaridade com a informação científica e tecnológica.

A nova onda pedagógica por projetos, também oriunda da França, mas com raízes no pragmatismo americano do século XIX, tenta ligar os conceitos científicos à vida no cotidiano do escolar. Os conhecimentos científicos e tecnológicos não são a mesma coisa que os conhecimentos escolares. O processo de ensino-aprendizagem funciona como uma mediação entre o objeto de ensino no qual se constituem os conhecimentos científicos e tecnológicos e o objeto a ensinar no qual se constituem os saberes escolares. Para que o primeiro se transforme no segundo todo é preciso articular um conjunto de saberes pedagógicos (didática, estratégias de ensino, sequenciação de conteúdos, teorias sobre currículo, métodos de avaliação), cerne do processo educacional. É disso que trata a educação como campo de conhecimento. É com isso que temos de interagir à nos aproximarmos do campo educacional. Seja para a geração de novos projetos pedagógicos seja para a geração de base de dados dos textos escolares. Por isso os sites educacionais são pontos de encontro entre saberes. 


\section{REFERÊNCIAS}

BREM, S.; ANDRÉA, J. Boyes Using critical thinking to conduct effective searches of online resources. Practical assessment, research \& evaluation, v. 7, n. 7. Disponível em: $<$ http://ericae.net/pare/vetvn.asp? $=7 \& \mathrm{n}=7$ >. Acesso em: 30 abr. 2002.

CUENCA, A. M. B. O usuário final da busca informatizada: avaliação da capacitação no acesso a bases de dados em biblioteca acadêmica. Ciência da Informação, v. 28, n. 3, p. 293-301, 1999.

DONADEL, E. R. Serviços e produtos informacionais em educação a distância: uma visão analítica das bibliotecas brasileiras. 2002. Dissertação (Mestrado em Biblioteconomia e Ciência da Informação) - Pontificia Universidade Católica de Campinas, Campinas.

GÓIS, A. O. et al. Serviço de referência aos usuários EAD/UNISA. São Paulo, Fundação Escola de Sociologia e Polítca. Curso de Especialização em Gerência de Sistemas e Serviços de Informação. (Monografia de final de curso)

HERNÁNDEZ, F. Transgressão e mudança na educação: os projetos de trabalho. Porto Alegre: Artmed, 1998.

LANGE, E. P. S. Ensino a distância via www: a contribuição da Ciência da Informação na construção e comunicação do conhecimento. 2002. Dissertação (Mestrado em Biblioteconomia e Ciência da Informação) - Pontifícia Universidade Católica de Campinas, Campinas.
LYOTARD, J-F. O pós-moderno. 3. ed. Rio de Janeiro: José Olympio, 1969.

MORAN, J. M.; MASSETTO, M. T.; BEHRENS, M. A. Novas tecnologias e mediação pedagógica. Campinas: Papirus, 2000.

MOSTAFA, S. P. ; TERRA, M. Fontes eletrônicas de informação: novas formas de comunicação e de produção do conhecimento. São Paulo em perspectiva, São Paulo, v. 12, n .4, out./dez. 1998. Disponível em:

$<$ http://www.geocities.com/spmostafa/bibli ografia.html >. 
Solange Puntel Mostafa

Profa. Dra. do Centro de Ciências

Humanas e da Comunicação UNIVERSIDADE DO VALE DO ITAJAí

Mestrado em Educação

Rua Uruguai, 458 - Centro - Itajaí(SC)

CEP: 88.302-202 - BRASIL solange@cehcom.univali.br

Artigo aceito para publicação em:

30 maio 2003 